\title{
Development of temperature indicator prototype: Cardpaper coated with chitosan intelligent films
}

\author{
Vinicius B. V. Maciel ${ }^{1 *}$, Cristiana M. P. Yoshida ${ }^{2}$ Telma T. Franco $^{1}$ \\ ${ }^{1}$ Department of Chemical Engineering, State University of Campinas, Campinas, Brazil; \\ *Corresponding Author: viniciusbvm@yahoo.com.br \\ ${ }^{2}$ Department of Exact and Earth Sciences, Federal University of Campinas, Diadema, Brazil
}

Received October 2013

\section{ABSTRACT}

An intelligent and biodegradable material packaging was developed based on a natural and thermal-sensitive pigment. Anthocyanin (ATH, $0.50 \mathrm{~g} / \mathbf{1 0 0 \mathrm { g } )}$ was incorporated into chitosan matrix films $(2 \mathrm{~g} / 100 \mathrm{~g})$ forming a chitosan intelligent film (C-ATH). The system is able to indicate the variation of temperature during distribution and storage chain of industrial products. The novelty of this work was an alternative packaging material that it is biodegradable and could inform any temperature variations on the range of $40^{\circ} \mathrm{C}-70^{\circ} \mathrm{C}$, by irreversible visual colour changes. The effects of temperature $\left(10^{\circ} \mathrm{C}, 30^{\circ} \mathrm{C}\right.$ and $50^{\circ} \mathrm{C}$ ) and luminosity $(0,500$ and $1000 \mathrm{~lx})$ were analyzed on C-ATH using an experimental design of 2 variables, measuring the colour parameters $\left(L^{*}, a^{*}, b^{*}\right)$ and mechanical properties (tensile strength, elongation break and Young's modulus) as responses. C-ATH suspensions were applied as a coating on cardpaper surface forming a temperature indicator prototype (TIP). C-ATH darkened after being exposed to temperatures above $50^{\circ} \mathrm{C}$ and luminosity of $1000 \mathrm{~lx}$ for 72 hours. TIP was obtained, without bubbles or defects, with reduced water absorption capacity. Irreversible visual colour change was verified on TIP exposed at $40^{\circ} \mathrm{C}$ independently of luminosity, turned gradually yellow. Chitosan suspensions containing ATH and applied as a coated on card paper sheets could be an alternative of biodegradable material for packaging system that indicates efficiently temperature changes. This indicator system has potential application temperature range of $40^{\circ} \mathrm{C}$ to $70^{\circ} \mathrm{C}$, such as food, pharmaceuticals, biological, agricultural and others products, that are highly dependent of storage temperature conditions.

\section{KEYWORDS}

Chitosan; Anthocyanin; Temperature Indicator; Coating; Card Paper

\section{INTRODUCTION}

The natural polymer films application in the packaging sector has been investigated due to their biodegradability and ability to retard the transport of moisture, gas, flavour and lipids. Films based on natural macromolecules, have been described in literature; however, industrial applications are still scarce. Among the natural polymers, chitosan forms resistant films with an efficient oxygen barrier [1,2].

Intelligent packaging is designed to monitor and communicate information about packed product quality and safety. Examples include time-temperature indicators, ripeness indicators, biosensors, radio frequency identification, etc. Colourimetric indicators can detect and monitor changes in the conditions of packed products [3] by visual colour variations.

Temperature greatly affects the quality and safety of thermal-sensitive products such as food, drugs and biological compounds. Variations in temperature conditions could promote undesirable physical and chemical deteriorations [4]. Time-temperature indicators (TTIs) are defined as simple, cost-effective and user-friendly devices to monitor, record and cumulatively indicate the overall influence of temperature traceability on the quality of the food product from the manufacturer to the consumer [5]. TTIs could be present as small self-adhesive labels that provide visual indications of temperature history during distribution and storage [6]. New types of TTIs have recently been studied; one example is a system based on the growth and metabolic activity of a strain of Lactobacillus sakei, which monitored food quality throughout the chilled-food chain [7]. Yan et al. [8] developed a new amylase-type TTI based on the reaction between amylase and starch solution, changing the colour from blue to 
yellow after temperature exposure from $4^{\circ} \mathrm{C}$ to $37^{\circ} \mathrm{C}$. Kato, Yoshida, Reis, Melo and Franco [9] developed a fast and colorimetric indicator system by combining chitosan as a three-dimensional biopolymer matrix and ferrous sulfate $\left(\mathrm{FeSO}_{4}\right)$ as a colorimetric indicator of hydrogen sulfide $\left(\mathrm{H}_{2} \mathrm{~S}\right)$ gas. Maciel, Yoshida and Franco [10] developed an intelligent and biodegradable temperature indicator packaging material based on a natural and heatsensitive pigment and chitosan solution dispersing on card paper.

In this study, the objective was to develop an intelligent and biodegradable alternative packaging material based on a natural polymer, chitosan, and thermal-sensitive pigment (anthocyanin, ATH) that visually change the colour after temperature exposition in a specific range. The efficiency response of this system was analysed by the changes in colour parameters. The mechanical properties were measured.

\section{MATERIALS AND METHODS}

\subsection{Materials}

Chitosan (Primex, Iceland; degree of acetylation (DA) of $18 \%$ and molecular weight $\left(\mathrm{M}_{\mathrm{w}}\right)$ of $\left.238,000 \mathrm{~g} \cdot \mathrm{mol}^{-1}\right)$, acetic acid (Synth, Brazil), anthocyanin (Christian Hansen, Brazil) and card paper triplex TP $250 \mathrm{~g} \cdot \mathrm{m}^{-2}$ (Suzano Papel e Celulose Ltd., Brazil) were used.

\subsection{Chitosan Intelligent Films (C-ATH)}

Film suspensions were prepared by dispersing chitosan $(2.00 \mathrm{~g} / 100 \mathrm{~g})$ in aqueous acetic acid [10]. The stoichiometric amount of acetic acid was calculated from sample weight, taking into account the value of DA to achieve the protonation of all the $\mathrm{NH}_{2}$ sites [2]. The suspensions were homogenized by magnetic stirring at room temperature for 45 minutes. The ATH $(0.50 \mathrm{~g} / 100 \mathrm{~g})$ was added to the filmogenic suspension and homogenized. Aliquots of 9.0 $\mathrm{mL}$ were poured into Petri dishes $(9.5 \mathrm{~cm})$ and dried at room temperature for 36 hours and then kept at $28^{\circ} \mathrm{C}$ in an incubator with forced air circulation for 24 hours. As the mass suspension used to cast the C-ATH was kept constant, the total solid content per gram of dried films was $28.2 \mathrm{~g} \cdot \mathrm{m}^{-2}$.

\subsubsection{Experimental Design}

The experimental design was applied to study the temperature and luminosity effects on the colour of C-ATH (Table 1). The luminosity range was from dark exposure $(0 \mathrm{l} \times)$ to simulation of supermarket light $(1000 \mathrm{l} \times)$. The time of exposure to temperature and luminosity conditions established was 72 hours.

\subsubsection{Mechanical Properties}

Tensile strength (TS), elongation at break $(\varepsilon)$ and
Table 1. Values range used in experimental design of two variables.

\begin{tabular}{cccc}
\hline Variables & -1 & 0 & +1 \\
\hline Temperature $\left({ }^{\circ} \mathrm{C}\right)$ & 10 & 30 & 50 \\
Luminosity $(\mathrm{lx})$ & 0 & 500 & 1000 \\
\hline
\end{tabular}

Young's Modulus (E) were determined on C-ATH based on ASTM Standard method D882 [11]. Films were cut into $25.4 \times 100.0 \mathrm{~mm}$ strips and preconditioned at $50 \%$ relative humidity (RH) and $25^{\circ} \mathrm{C} \pm 2^{\circ} \mathrm{C}$ for 48 hours. Measurements were made using a TA.XT2 texture analyzer (Stable Micro Systems, Godalming, UK). The initial grip separation was set at $50 \mathrm{~mm}$ and crosshead speed at $1 \mathrm{~mm} \cdot \mathrm{s}^{-2}$. There were at least ten replicates per experiment. Film thickness was measured using a micrometer (Mitutoyo Mfg Co. Ltd., Japan) and measurements were taken at five random positions on the film, using the average values to calculate film properties.

\subsubsection{Scanning Electron Microscopy (SEM)}

SEM analysis was performed on fractured cross-sections and the surface of gold-sputtered C-ATH films using a LEO 440i scanning electron microscope (LEO Electron Microscopy Ltda., England), operating at $10 \mathrm{kV}$ and $100 \mathrm{pA}$ [10]. Chitosan films (CF) without anthocyanin was studied as reference.

\subsection{Temperature Indicator Prototype (TIP)}

Sheets of card paper $\left(0.045 \mathrm{~m}^{2}\right)$ were coated with CATH suspensions. The C-ATH suspension was spread on the card paper surface using $80 \mu \mathrm{m}$ wire bar coater (TKB Erichsen, Brazil). The coated paper sheets were dried in an oven at $150^{\circ} \mathrm{C}$ for $90 \mathrm{~s}$.

\subsubsection{Water Absorption-Cobb Test}

Water absorption capacity was determined in accordance with standard ASTM D3285 [12]. T441om-90.27 The weight gain was measured using Mettler AE 163 analytical scales. The results are expressed in $\mathrm{g} \mathrm{m}^{-2}$. There were at least 15 replicates per experiment. Samples were preconditioned at $50 \% \mathrm{RH}$ and $25{ }^{\circ} \mathrm{C}$ for 48 hours in a desiccator.

\subsubsection{Taber Stiffness}

Taber stiffness was determined using standard method ASTM D5342 [13]. Uncoated and coated cardpaper sheets were cut into samples of $38 \times 70 \mathrm{~mm}^{2}$ in the machine direction (MD) and the cross-machine direction (CD) using a guillotine (Regmed, Brazil). Taber stiffness was measured at an angle of $15^{\circ}$ using Taber stiffness equipment (model RI 5000, Regmed, Brazil). Results are expressed in $\mathrm{mN}$. There were at least 15 replicates per 
experiment. Samples were preconditioned at 50\% $\mathrm{RH}$ and $25^{\circ} \mathrm{C}$ for 48 hours in a desiccator.

\subsection{Colour Response Efficiency Measurement}

The colour parameters $\left(\mathrm{L}^{*}, \mathrm{a}^{*}, \mathrm{~b}^{*}\right)$ of C-ATH and TIP were measured at different periods of times after temperature and luminosity exposition. A Chroma Meter CR 400 colourimeter (Konica Minolta, Japan) was used. The parameter $\mathrm{L}^{*}$ represents the lightness of colours from 0 (dark) to 100 (light), a ${ }^{*}$ is a measure of greenness/redness and $b^{*}$ is the grade of blueness/yellowness. Both $a^{*}$ and $b^{*}$ scales range from -60 to +60 . The transformation of $\mathrm{a}^{*}$ and $\mathrm{b}^{*}$ into geometric values (hue angle $-\mathrm{h}_{\mathrm{ab}}$ ) for $\mathrm{C}$ ATH is a better predictor variable of sensory perception in experimental design application. The $\mathrm{h}_{\mathrm{ab}}\left(0^{\circ}-360^{\circ}\right)$ was obtained by arctan $\mathrm{b}^{*} / \mathrm{a}^{*}$ and was used to express the characteristic/dominant colour [14]. According to several authors [14,15] this conversion is necessary to obtain results in the experimental design due to interaction between parameters $a^{*}$ and $b^{*}$, where a change in one usually does not occur without changing the other. The CATH was exposed to experimental design conditions and the TIP was exposed to a range of temperatures $\left(10^{\circ} \mathrm{C}\right.$ $70^{\circ} \mathrm{C}$ ) and 0 and $1000 \mathrm{l} \times$. There were three replicates per experiments.

\subsection{Statistical Analysis}

Statistical analysis was carried out with the Statistic version 7.0 program (Statistic Inc., USA) and differences between the means were detected by the Tukey multiple comparison test.

\section{RESULTS AND DISCUSSION}

Initially C-ATH was obtained to evaluate the colour response efficiency of the system as temperature indicator. Homogeneous, transparent, dark violet films were obtained and following drying, were easily removed from the support plates, forming a flexible and resistant matrix.

\subsection{Experimental Design}

The colour parameters $\mathrm{L}^{*}$ and $\mathrm{h}_{\mathrm{ab}}$ of C-ATH were characterized after $72 \mathrm{~h}$ under exposure to temperatures and luminosities (Table 2).

The effects of temperature and luminosity on colour variations of C-ATH were significant for a confidence level of $90 \%$ for parameters $L^{*}$ and $h_{a b}$ (Figure 1). The initial purple colour of the films gradually turned dark. Increasing the temperature from $10^{\circ} \mathrm{C}$ to $50^{\circ} \mathrm{C}$, parameters $\mathrm{L}^{*}$ and $\mathrm{h}_{\mathrm{ab}}$ increased to 5.02 and 3.40, respectively. Although increasing the luminosity from 0 to $1000 \mathrm{l} \times$, a
Table 2. Matrix of experimental design $2^{2}$, colour parameters and mechanicals properties of C-ATH films.

\begin{tabular}{|c|c|c|c|c|c|c|c|}
\hline \multirow{3}{*}{ Tests } & \multicolumn{2}{|c|}{ Independent Variables } & \multicolumn{5}{|c|}{ Properties } \\
\hline & Temperature & Luminosity & \multirow{2}{*}{$\mathrm{L}^{*}$} & \multirow{2}{*}{$\mathrm{h}_{\mathrm{ab}}\left({ }^{\circ}\right)$} & \multirow{2}{*}{$\frac{\varepsilon}{(\%)}$} & TS & \multirow[b]{2}{*}{ (GPa) } \\
\hline & $\left({ }^{\circ} \mathrm{C}\right)$ & (lx) & & & & (MPa) & \\
\hline 1 & $-1(10)$ & $-1(0)$ & 45.52 & 274.13 & 3.21 & 60.71 & 3.12 \\
\hline 2 & $+1(50)$ & $-1(0)$ & 48.73 & 307.29 & 2.91 & 66.51 & 3.15 \\
\hline 3 & $-1(10)$ & $+1(1000)$ & 45.16 & 298.08 & 3.61 & 60.62 & 2.50 \\
\hline 4 & $+1(50)$ & +1 (1000) & 45.85 & 323.19 & 3.38 & 50.04 & 2.71 \\
\hline 5 & $0(30)$ & $0(500)$ & 45.77 & 312.29 & 2.56 & 67.64 & 3.14 \\
\hline 6 & $0(30)$ & $0(500)$ & 45.70 & 311.45 & 2.53 & 67.67 & 3.14 \\
\hline 7 & $0(30)$ & $0(500)$ & 46.09 & 312.01 & 2.56 & 67.63 & 3.14 \\
\hline
\end{tabular}

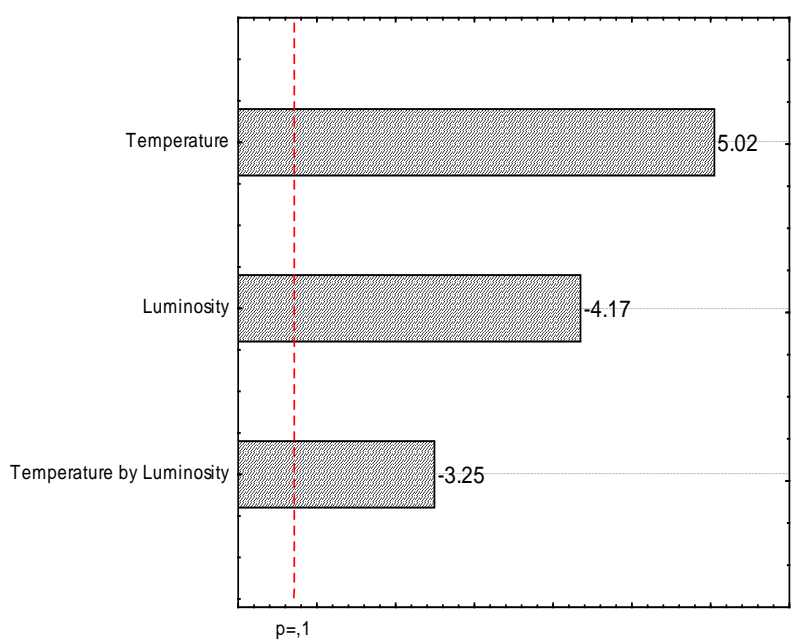

(a)

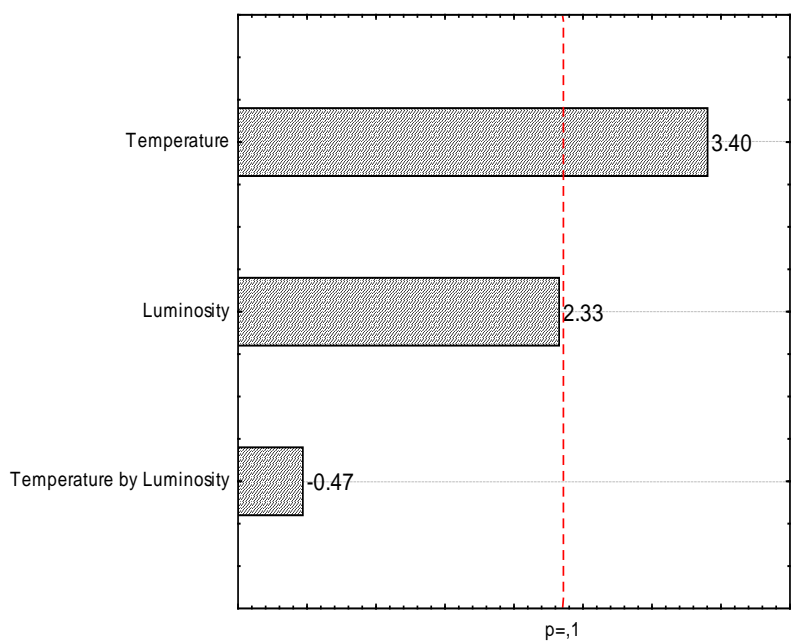

(b)

Figure 1. Effect of temperature and luminosity on variations in colour of C-ATH: (a) Parameter ${ }^{*}$ and (b) Parameter $h_{a b}$. 
process of discolouration was observed with the reduction in $\mathrm{L}^{*}$. The combined temperature and luminosity decreased the $\mathrm{L}^{*}$ in 3.25 the $\mathrm{C}$-ATH became lighter.

Shaked-Sachray, Weiss, Reuveni, Nissim-Levi and Oren-Shamir [16] studied the combined effect of elevated temperatures and metal concentrations on the accumulation of ATH in aster flowers and observed that the anthocyanin degraded and became discoloured at higher temperatures (higher than $30^{\circ} \mathrm{C}$ ). Significant changes in $b^{*}$ values were also found by Alighourchi and Barzegar [17] for anthocyanins in pasteurised pomegranate juice stored at $4^{\circ} \mathrm{C}, 20^{\circ} \mathrm{C}$ and $37^{\circ} \mathrm{C}$ for 210 days. In their study, $\mathrm{L}^{*}, \mathrm{a}^{*}$ and $\mathrm{b}^{*}$ values decreased and the most significant colour change was observed after storage at $20^{\circ} \mathrm{C}$ and $37^{\circ} \mathrm{C}$. This change was attributed to the degradation of anthocyanin. According to Lauro and Francis [18], the anthocyanins could change with temperature, light, oxygen, presence of sugars and enzyme, $\mathrm{pH}$ and presence of proteins and metal ions [19-22], producing polymers with decreased stability.

Temperature and luminosity had not affected $\varepsilon$ and TS significantly (Table 2). For E, only the luminosity had a slightly significant effect $(p \leq 0.1)$. Increasing luminosity from 0 to $1000 \mathrm{l} \times$, E decreased in order to $19.9 \%$ at $10^{\circ} \mathrm{C}$ and $14.0 \%$ at $50^{\circ} \mathrm{C}$. These results are indicating that flexibility and strength of ATH-CF were maintained similar to the initial condition.

The good mechanical properties of CF and ATH-CF could be related with the microstructures (Figure 2). A compact and cohesive structure without pores or cracks was observed in CF (Figure 2(a)). No significant difference was observed between CF and ATH-CF structures (Figure 2(b)). ATH was entrapped in the tridimensional matrix forming a uniform structure films. Yoshida, Oliveira-Junior and Franco [1] found similar results for CF and CF with palmitic acid.

\subsection{Film Card Paper System (TIP)}

C-ATH suspensions were applied as a coating on card paper surface forming TIP system. The TIP drying process time was $90 \mathrm{~s}$, which was faster than the total film drying process $(60 \mathrm{~h}$ ) that could be a commercial advantage.

C-ATH suspensions formed a homogeneous card paper coating without bubbles or defects. The systems were submitted to different temperature and luminosity conditions during 72 hours. An irreversible and gradual change in colour exposition of the TIP was visually observed after 72 hours at different temperature and luminosity conditions (Figure 3). A more pronounced colour change was observed after luminosity exposition. Studying the colour stability of berry anthocyanin, Rein [19] found that the exposition at higher luminosities accelerated ATH discolouration. The parameter $b^{*}$ values increased

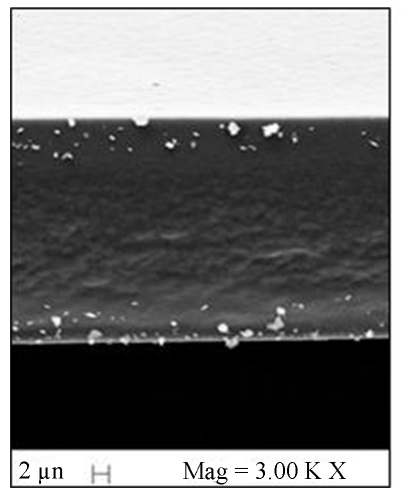

(a)

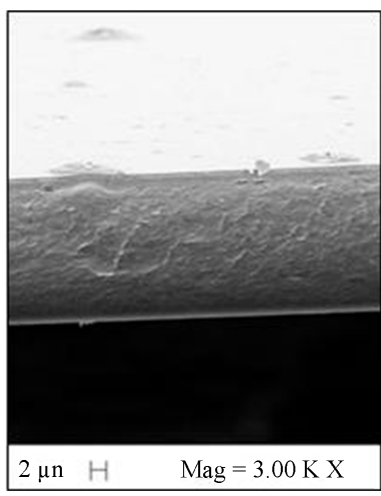

(b)
Figure 2. SEM Micrographs for (a) CF, (b) C-ATH containing $0.25 \%$ ATH.

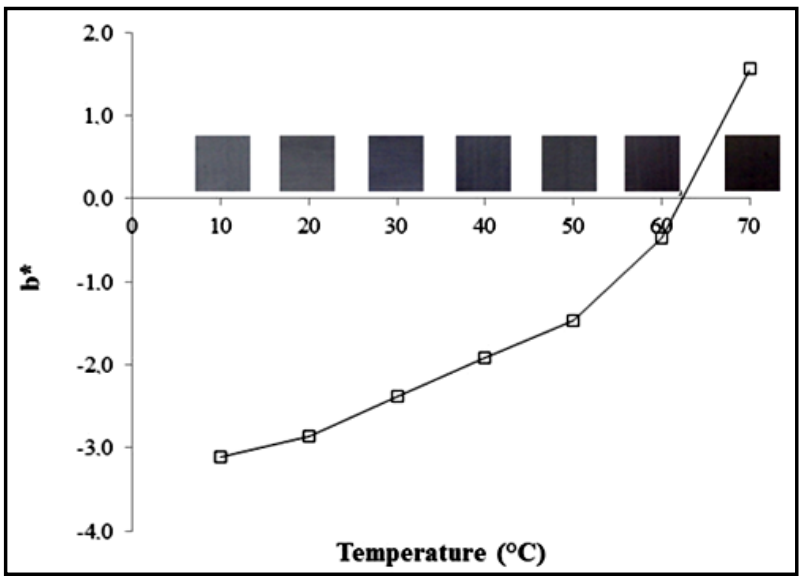

(a)

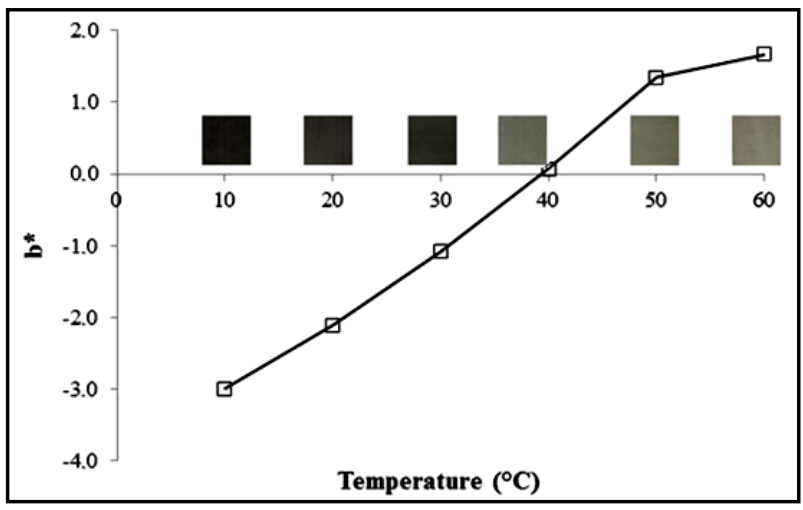

(b)

Figure 3. The visual and $b^{*}$ colour parameter changes on TIP system exposed to different temperatures and luminosities: (A) $0 \mathrm{l} \times$ and (b) $1000 \mathrm{l} \times$.

in TIP after 0 and $1000 \mathrm{l} \times$ exposition.

Colour change on the TIP could be associated with ATH molecules chemical structure. Thermal degradation can produce changes in ATH structures that depend on the severity and heating conditions. The mechanisms of ATH degradation are still relatively unknown. Chemical 
structures and the presence of other organic acids have a strong influence [22]. Markakis, Livingstone and Fillers [23] suggested that the pyrylium ring of ATH opens, forming a chalcone structure as a first degradation step. Chalcone is derived from three acetates and one cinnamic acid. It has a yellow pigmentation and is a precursor of the biosynthesis of flavonoid. Adams [24] reported that ATH could decompose upon heating into a chalcone structure and be further transformed into a coumarin glucoside derivative by the loss of the B-ring.

The ATH discolouration was observed in blue flowers [16], pomegranate juice [17], vegetables extracts [25] and fruits purees [26] after exposure to temperatures higher than $30^{\circ} \mathrm{C}$. The discolouration process is usually accelerated with luminosity [23].

\subsection{Properties of TIP}

The grammage, water absorption capacity and Taber stiffness results for uncoated and coated card paper are shown in Table 2. The C-ATH coating did not significantly change the grammage of card paper. Water resistance is an important property which can determine the behaviour of card paper in various applications. The water absorption of the TIP decreased significantly applying C-ATH coating.

According to Aider [27], chitosan films have the ability to avoid moisture loss or water absorption and could act as a reinforcement layer. Bordenave, Grelier, Pichavant and Coma [28] studied the potentiality of bioactive food packaging based on chitosan-coated papers and show that chitosan film improved the water absorption of paper despite the very low amount of total solids. The incorporation of chitosan as a papermaking additive in paper and paperboard production or as a surface coating, had previously been investigated [29-32]. Different concentrations of chitosan were applied as a coating additive in paper and paperboard making, and it was observed that when increased chitosan concentration from 0.1 to $0.75 \%(w / w)$, the water absorption decreased significantly [29]. The greaseproof paper coated with chitosan films did not provide an extra barrier against water absorption [30]. The Taber stiffness values were statistically different when applied C-ATH coating on card paper surface as compared to uncoated card paper (Table 3 ). The resistance and flexiblility of C-ATH strengthened the cellulose fiber interbonds. Chitosan films had a positive impact on the mechanical properties of coated paper [32].

\section{CONCLUSION}

An efficient and irreversible temperature indicator material was obtained for a specific range (from $40^{\circ} \mathrm{C}$ to $70^{\circ} \mathrm{C}$ ) using biodegradable materials (chitosan, card paper and ATH). The TIP changed the colour from violet to yellow after temperature exposition. Luminosity acceler-
Table 3. Grammage, Cobb Test and Taber stiffness of TIP [10].

\begin{tabular}{|c|c|c|c|}
\hline \multirow{2}{*}{ Samples } & Grammage & Water absorption & Taber Stiffness (mN.m) \\
\hline & $\left(g \cdot m^{-2}\right)$ & $\left(g \cdot m^{-2}\right)$ & MD \\
\hline $\begin{array}{l}\text { Uncoated } \\
\text { cardpaper }\end{array}$ & $252.71 \pm 1.88^{\mathrm{a}}$ & $45.48 \pm 1.76^{\mathrm{a}}$ & $5.60 \pm 0.16^{\mathrm{a}} 12.97 \pm 0.21^{\mathrm{a}}$ \\
\hline TIP system & $253.17 \pm 1.71^{\mathrm{a}}$ & $35.41 \pm 1.66^{\mathrm{b}}$ & $6.43 \pm 0.17^{\mathrm{b}} 14.15 \pm 0.09^{\mathrm{b}}$ \\
\hline
\end{tabular}

a, b, c Means in the same column with different superscripts differ significantly $(p \leq 0.05)$ in accordance with Tukey's test.

ated the ATH molecule degradation. The advantages of this temperature indicator were the simple manufacturing process, use of natural compounds that are food safety contact, the biodegradability and low cost. This indicator system has potential applications in different areas such as food, pharmaceuticals, biological, agricultural and others products, that are highly dependent of storage temperature conditions.

\section{ACKNOWLEDGEMENTS}

The financial support of CNPq, FAPESP, CAPES and Suzano Papéis e Celulose Ltd.

\section{REFERENCES}

[1] Yoshida, C.M.P., Oliveira-Junior, E.N. and Franco, T.T. (2009) Chitosan tailor-made films: The effects of additives on barrier and mechanical properties. Packaging Technology and Science, 22, 161-170. http://dx.doi.org/10.1002/pts.839

[2] Notin, L., Viton, C., David, L., Alcouffe, P., Rochas, C. and Domard, A. (2006) Morphology and mechanical properties of chitosan fibers obtained by gel-spinning: Influence of the dry-jet-stretching step and ageing. Acta Biomaterialia, 2, 387-402. http://dx.doi.org/10.1016/j.actbio.2006.03.003

[3] Ahvenainen, R. (2003) Active and inteligente packaging: An introduction. In: Ahvenainen, R., Ed., Novel Food Packaging Techniques. CRC Press, Boca Raton, 5-21. http://dx.doi.org/10.1533/9781855737020.1.5

[4] Shimoni, E., Anderson, E.M. and Labuza, T.P. (2001) Reliability of time temperature indicators under temperature abuse. Journal of Food Science, 66, 1337-1340. http://dx.doi.org/10.1111/j.1365-2621.2001.tb15211.x

[5] Wanihsuksombat, C., Hongtrakul, V. and Suppakul, P. (2010) Development and characterization of a prototype of a lactic acid-based time-temperature indicator for monitoring food product quality. Journal of Food Engineering, 100, 427-434. http://dx.doi.org/10.1016/j.jfoodeng.2010.04.027

[6] Yam, K.L., Takhistov, P.T. and Miltz, J. (2005) Intelligent packaging: Concepts and applications. Journal of Food Science, 70, R1-R10. http://dx.doi.org/10.1111/j.1365-2621.2005.tb09052.x

[7] Vaikousi, H., Biliaderis, C.G. and Koutsoumanis, K.P. (2008) Development of a microbial time-temperature in- 
dicator prototype for monitoring the microbiological quality of chilled foods. Applied and Environmental Microbiology, 74, 3242-3250. http://dx.doi.org/10.1128/AEM.02717-07

[8] Yan, S., Huawei, C., Limin, Z., Fazheng, R., Luda, Z. and Hengtao, Z. (2008) Development and characterization of a new amylase type time-temperature indicator. Food Control, 19, 315-319. http://dx.doi.org/10.1016/j.foodcont.2007.04.012

[9] Kato Jr, E.T., Yoshida, C.M.P., Reis, A.B., Melo, I.S. and Franco, T.T. (2011) Fast detection of hydrogen sulphide using a biodegradable colorimetric indicator system. $\mathrm{Po}^{-}$ lymer International, 60, 951-956. http://dx.doi.org/10.1002/pi.3095

[10] Maciel, V.B.V., Yoshida, C.M.P. and Franco, T.T. (2012) Development of a prototype of a colourimetric temperature indicator for monitoring food quality. Journal of Food Engineering, 111, 21-27. http://dx.doi.org/10.1016/j.jfoodeng.2012.01.037

[11] ASTM (1995) Tensile properties of thin plastic sheeting. Annual Book of ASTM Standards, Philadelphia, D882.

[12] ASTM (1999) Water absorptiveness of nonbibulous paper and paperboard (Cobb Test). Annual Book of ASTM Standards, Philadelphia, D3285.

[13] ASTM (2002) Resistance to bending of paper and paperboard (Taber-type tester in basic configuration). Annual Book of ASTM Standards, Atlanta, D5342.

[14] Wyszecki, G. and Stiles, W.S. (1967) Color science: Concepts and methods, quantitative data and formulas. John Wiley \& Sons Inc., London.

[15] Ellouze, M. and Augustin, J.C. (2010) Applicability of biological time temperature integrators as quality and safety indicators for meat products. International Journal of Food Microbiology, 138, 119-129.

http://dx.doi.org/10.1016/j.ijfoodmicro.2009.12.012

[16] Shaked-Sachray, L. Weiss, D., Reuveni, M., Nissim-Levi, A. and Oren-Shamir, M. (2002) Increased anthocyanin accumulation in aster flowers at elevated temperature due to magnesium treatment. Physiologia Plantarum, 114, 559-565. http://dx.doi.org/10.1034/j.1399-3054.2002.1140408.x

[17] Alighourchi, H. and Barzegar, M. (2009) Some physiccochemical characteristics and degradation kinetic of anthocyanin of reconstituted pomegranate juice during storage. Journal of Food Engineering, 90, 179-185. http://dx.doi.org/10.1016/j.jfoodeng.2008.06.019

[18] Lauro, G.J. and Francis, J.F. (2000) Natural food colorants. In: Lauro, G.J. and Francis, J.F., Eds., Anthocyanins, Marcel Dekker, New York, 237-252.

[19] Rein, M. (2005) Copigmentation reactions and color stability of berry anthocyanins. Dissertation, University of Helsinki, Helsinki.

[20] Wallace, T.C. and Giusti, M.M. (2008) Determination of color, pigment, and phenolic stability in yogurt systems colored with nonacylated anthocyanins from Berberis boliviana l. as compared to other natural/synthetic colorants. Journal of Food Science, 73, C241-C248. http://dx.doi.org/10.1111/j.1750-3841.2008.00706.x
[21] Aramwit, P., Bang, N. and Srichana, T. (2010) The properties and stability of anthocyanins in mulberry fruits. Food Research International, 43, 1093-1097. http://dx.doi.org/10.1016/j.foodres.2010.01.022

[22] Patras, A., Brunton, N.P., O’Donnell, C. and Tiwari, B.K. (2010) Effect of thermal processing on anthocyanin stability in foods; Mechanisms and kinetics of degradation. Trends in Food Science and Technology, 21, 3-11. http://dx.doi.org/10.1016/j.tifs.2009.07.004

[23] Markakis, P., Livingstone, G.E. and Fillers, G.R. (1957) Quantitative aspects of strawberry-pigment degradation. Journal of Food Science, 22, 117-130. http://dx.doi.org/10.1111/j.1365-2621.1957.tb16991.x

[24] Adams, J.B. (1973) Thermal degradation of anthocyanins with particular reference to the 3-glycosides of cyanidin. I. In acidified aqueous solution at $100^{\circ} \mathrm{C}$. Journal of the Science of Food and Agriculture, 24, 747-762. http://dx.doi.org/10.1002/jsfa.2740240702

[25] Bolivar, A.C.C. and Cisveros-Zevallos, L. (2004) Stability of anthocyanin-based aqueous extract of Andean purple corn and red-flushed sweet potato compared to synthetic and natural colourants. Food Chemistry, 86, 69-77. http://dx.doi.org/10.1016/j.foodchem.2003.08.011

[26] Patras, A., Brunton, N.P., Da Pieve, S. and Butler, F. (2009) Impact of high pressure processing on total antioxidant activity, phenolic, ascorbic acid, anthocyanin content and colour of strawberry and blackberry purées. Innovative Food Science and Emerging Technology, 10, 308-313. doi: 0.1016/j.ifset.2008.12.004

[27] Aider, M. (2010) Chitosan application for active bio-based films production and potential in the food industry: Review. Food Science and Technology, 43, 837-842. http://dx.doi.org/10.1016/j.lwt.2010.01.021

[28] Bordenave, N., Grelier, S., Pichavant, F. and Coma, V. (2007) Water and moisture susceptibility of chitosan and paper-based materials: Structure-property relationships. Journal of Agricultural and Food Chemistry, 55, 94799488. http://dx.doi.org/10.1021/jf070595i

[29] Kuusipalo, J., Kaunisto, M., Laine, A. and Kellomäki, M. (2005) Chitosan as a coating additive in paper and paperboard. Tappi Journal, 4, 17-21.

[30] Kjellgren, H., Gällstedt, M., Engström, G. and Järnström, L. (2006) Barrier and surface properties of chitosancoated greaseproof paper. Carbohydrate Polymers, 65, 453460. http://dx.doi.org/10.1016/j.carbpol.2006.02.005

[31] Fernandes, S.C.M., Freire, C.S.R., Silvestre, A.J.D., Neto, C.P., Gandini, A., Desbriéres, J., Blanc, S., Ferreira, R.A.S. and Carlos, L.D. (2009) A study of the distribution of chitosan onto and within a paper sheet using a fluorescent chitosan derivative. Carbohydrate Polymers, 78, 760-766. http://dx.doi.org/10.1016/j.carbpol.2009.06.012

[32] Fernandes, S.C.M., Freire, C.S.R., Silvestre, A.J.D., Desbrières, J., Gandini, A. and Neto, C.P. (2010) Production of coated papers with improved properties by using a water-soluble chitosan derivative. Industrial and Engineering Chemistry Research, 49, 6432-6438. http://dx.doi.org/10.1021/ie100573z 